\section{Fourier Transform Infrared Spectros- copy as a Novel Approach for Analyz- ing the Biochemical Effects of Anionic Surfactants on a Surfactant-Degrading Arcobacter butzleri Strain}

\author{
Omer Faruk Sarioglu, ${ }^{\text {a }}$ Yusuf Talha

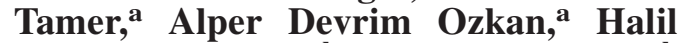 \\ Ibrahim Atabay, ${ }^{b, c}$ Celenk Molva, ${ }^{b}$ \\ Turgay Tekinay ${ }^{\mathrm{a}, *}$ \\ a Bilkent University, National Nanotechnology Research \\ Center, Bilkent, Ankara 06800, Turkey \\ ${ }^{\mathrm{b}}$ Izmir Institute of Technology, Department of Food \\ Engineering, Faculty of Engineering, Urla, Izmir 35430, \\ Turkey \\ c Sifa University, Department of Medical Microbiology, \\ Faculty of Medicine, Izmir 35100, Turkey
}

\begin{abstract}
Anionic surfactant-biodegrading capability of an Arcobacter butzleri strain was analyzed under aerobic conditions. The A. butzleri isolate displayed efficient surfactant-biodegrading capacity for sodium dodecyl sulfate (SDS) at concentrations of up to $100 \mathrm{mg} / \mathrm{L}$ in 6 days, corresponding to $\mathbf{9 9 . 0 \%}$ removal efficiency. Fourier transform infrared spectroscopy was applied to observe the effects of varying concentrations of SDS on the biochemistry of bacterial cells. Results suggest that protein secondary structures were altered in bacterial cells at sufficiently high SDS concentrations, concurrent with SDS biodegradation.
\end{abstract}

Index Headings: Arcobacter butzleri; Anionic surfactant biodegradation; Sodium dodecyl sulfate; Fourier transform infrared spectroscopy; FT-IR.

\section{INTRODUCTION}

Detergent surfactants enjoy widespread use and are a major cause of environmental pollution. ${ }^{1}$ The U.S. Environmental Protection Agency reports that surfactants display endocrinedisrupting properties and constitute a health hazard to both animals and humans. ${ }^{2}$ Detergent pollution in freshwater sources therefore is a major problem, ${ }^{3}$ and removal of surfactants from wastewater systems and natural freshwater sources is of substantial importance.

Bioremediation is an alternative to chemical surfactant removal methods and involves the use of microorganisms or their enzymes to clean industrial and municipal plant wastewaters. Compared with chemical methods, bioremediation is a harmless ${ }^{4}$ and more efficient way to remove a wide variety of undesirable chemicals from the environment, including heavy metals, oils, and surfactants. ${ }^{5}$ European Union

Received 23 January 2012; accepted 17 December 2012.

* Author to whom correspondence should be sent. E-mail: ttekinay@ bilkent.edu.tr.

DOI: $10.1366 / 12-06609$
Ministries of Environment recommend the use of microorganisms for degradation of detergents as an alternative to chemical methods. ${ }^{6}$ Biodegradable surfactants have been used to increase the efficiency of microbial degradation. For instance, branched, non-biodegradable propylene tetramer benzene sulfonate-type surfactants were replaced by linear alkylbenzene sulfonate type surfactants, which are $97-99 \%$ biodegradable by microorganisms under aerobic conditions. However, the negative environmental effects of surfactants persist, since microorganisms can only degrade certain surfactants at a very low rate under natural conditions. ${ }^{7}$ Determination of physical parameters for optimal degradation capacity, as well as the isolation and construction of efficient bacterial consortia, is required for efficient biodegradation of those pollutants. There is extensive research aimed at obtaining better degradation efficiencies for surfactant removal under different physical and environmental conditions.

The genus Arcobacter comprises gram-negative, non-sporeforming, fastidious, microaerophilic, motile, and slightly curved rod- or spiral-shaped bacteria, and belongs to the Proteobacteria rRNA super family VI. ${ }^{8}$ This genus is a potential candidate for use in bioremediation efforts, as the bioremediation capability of Arcobacter is similar to the bioremediation capabilities of Pseudomonas and Klebsiella, which are widely used in bioremediation studies. ${ }^{9}$ Otth et al. ${ }^{10}$ reported on Arcobacter strains that displayed resistance to a number of heavy metals and therefore are promising candidates that could be used for bioremediation, alone or in a consortium with other bacteria.

In recent years, a number of different techniques were successfully utilized in bacterial biodegradation studies. Highpressure liquid chromatography (HPLC) has been employed for observing the ultimate biodegradation of surfactants by bacteria $^{9,10}$ and FT-IR was suggested as an alternative method to screen the degradation of organic pollutants. ${ }^{11,12}$ Application of FT-IR for screening chemical interactions among different substances is well known and has the potential to be used in biodegradation studies to determine the reactions by which the chemical of interest is remediated, sorbed, or otherwise rendered less destructive.

In this report, a previously isolated strain of $A$. butzleri was utilized as an alternative bacterial remediative agent capable of rapidly degrading sodium dodecyl sulfate (SDS) in concentrations up to $100 \mathrm{mg} / \mathrm{L}$. Furthermore, FT-IR was applied as a novel approach for rapid screening of biochemical interactions that take place during the biodegradation process and for its effects on the biochemistry of bacterial cells.

\section{MATERIALS AND METHODS}

Culture Media and Procurement of Bacteria. LuriaBertani (LB) broth was utilized as the base growth medium in this study. ${ }^{13,14}$ This medium was supplemented with M9 minimal salts, including $6.3 \mathrm{~g} / \mathrm{L} \mathrm{Na} \mathrm{HPO}_{4}, 3.0 \mathrm{~g} / \mathrm{L} \mathrm{KH}_{2} \mathrm{PO}_{4}$, $0.5 \mathrm{~g} / \mathrm{L} \mathrm{NaCl}$, and $1.0 \mathrm{~g} / \mathrm{L} \mathrm{NH}_{4} \mathrm{Cl}^{15}{ }^{15}$ All reagents were obtained from Sigma-Aldrich (St. Louis, MO). The A. butzleri strain 
used in this study was isolated and characterized as previously described. ${ }^{16}$ In brief, Arcobacter enrichment broth was utilized to selectively isolate Arcobacter species from chicken carcasses. The A. butzleri isolate was identified at the species level by a multiplex polymerase chain reaction assay. No specific designation was given to the isolated strain. This strain was grown in LB broth and on visible growth; new inocula were prepared for surfactant-biodegradation studies.

Shaking-Culture Experiments for Sodium Dodecyl Sulfate (SDS) Biodegradation. LB-broth samples containing $0,10,40,100$, and $3000 \mathrm{mg} / \mathrm{L}$ SDS were utilized for resistance and degradation studies. Bacterial inocula were grown in SDS concentrations of up to $100 \mathrm{mg} / \mathrm{L}$ to observe surfactantdegrading capability of $A$. butzleri at varying initial surfactant concentrations, while $3000 \mathrm{mg} / \mathrm{L}$ SDS-containing medium was utilized to observe how high concentrations of SDS influence bacterial growth. Bacterial growth rates were determined by measurements of optical density at a $600 \mathrm{~nm}$ wavelength $\left(\mathrm{OD}_{600}\right)$. Samples were incubated at $30{ }^{\circ} \mathrm{C}$ and $125 \mathrm{rpm}$. Remaining SDS concentrations were determined on days 0,1 , 2,3 , and 6 by a methylene blue active substances (MBAS) assay, as previously described, ${ }^{17}$ in which methylene blue binds with anionic surfactants in a liquid and gives an absorbance peak at $652 \mathrm{~nm}$. All tests were done in triplicate unless otherwise noted.

Fourier Transform Infrared Spectroscopy (FT-IR) Analysis. A. butzleri samples were inoculated in $50 \mathrm{~mL}$ of $\mathrm{M} 9$ salts supplemented LB medium containing 0, 40, 100, and $3000 \mathrm{mg} /$ L SDS. Samples were taken on days 0,1 , and 3 (1 mL for each aliquot) and diluted to identical $\mathrm{OD}_{600}$ values for each day, if it was required. Samples were then centrifuged at $14000 \mathrm{rpm}$ for 5 min, the supernatants were removed, and the remaining pellets were washed with physiological saline $(0.90 \%$ [w/v] of $\mathrm{NaCl}$ ) twice and stirred with distilled water. Fifty microliters of this final solution was dried on a 96 -well plate at $45^{\circ} \mathrm{C}$ for $1 \mathrm{~h}$. After drying, the 96-well plate was utilized in FT-IR transmittance analysis by using a Nicolet 6700 FT-IR Spectrometer (Thermo-Scientific, Waltham, MA). OMNIC software (Thermo-Scientific) was used for measurements and basic modifications such as baseline and background corrections. Background corrections for $\mathrm{H}_{2} \mathrm{O}$ and $\mathrm{CO}_{2}$ were carried out for each analysis. Experiments were repeated for four times, and duplicate samples were utilized in each experiment.

Protein Secondary-Structure Analysis. All protein secondary-structure analyses were made with OMNIC software. Second-derivative analysis of the amide I region (1600-1700 $\mathrm{cm}^{-1}$ ) was performed to determine how protein secondary structures were affected by exposure to high concentrations of SDS. Curve-fitting analysis of the amide I region was performed by Voigt profiling to estimate approximate ratios of the subgroups of protein secondary structures with respect to the total protein content, which are adopted at the regions of $1610 \mathrm{~cm}^{-1}$ for aromatic rings, $1630 \mathrm{~cm}^{-1}$ and $1678 \mathrm{~cm}^{-1}$ for $\beta$ sheets, $1645 \mathrm{~cm}^{-1}$ for random coils, $1661 \mathrm{~cm}^{-1}$ for $\alpha$-helices, and $1691 \mathrm{~cm}^{-1}$ for turns. ${ }^{18}$ All tests were done in duplicate.

Scanning Electron Microscopy (SEM). The A. butzleri isolate was inoculated in $50 \mathrm{~mL}$ of M9 salts supplemented LB medium with and without $3000 \mathrm{mg} / \mathrm{L} \mathrm{SDS}$ and incubated for 48 $\mathrm{h}$ at $125 \mathrm{rpm}$ and $30{ }^{\circ} \mathrm{C}$. Two-tenths of a milliliter of evenly distributed bacteria-containing medium was taken for each sample. The bacteria-containing medium was poured onto a filter membrane and dried at $45^{\circ} \mathrm{C}$ for $1 \mathrm{~h}$. After drying, filter membranes were fixed for the SEM analysis as described by
Greif et al. ${ }^{19}$ Images were taken with a Quanta 200 FEG scanning electron microscope (FEI Instruments, Pittsburgh, PA).

\section{RESULTS}

Biodegradation Capability of $A$. butzleri at Different Sodium Dodecyl Sulfate (SDS) Concentrations. Growth curves of samples, excluding the $3000 \mathrm{mg} / \mathrm{L}$ sample, were very similar throughout the experiment period (Fig. 1A), while a marked decrease in growth was present in the $3000 \mathrm{mg} / \mathrm{L}$ sample after day 1 . In terms of surfactant removal, the $A$. butzleri isolate showed considerable biodegradation capacity for each tested concentration of SDS, excluding the $3000 \mathrm{mg} / \mathrm{L}$ sample, in which little growth was observed (Fig. 1B). Biodegradation of SDS varied between $80 \%$ (10 mg/L sample) and $99 \%$ (100 mg/L sample) in 6 days.

Fourier Transform Infrared Spectroscopy (FT-IR) Analysis Results.In this study, most of the specific regions and chemical groups of FT-IR are determined based on Movasaghi et al.'s report for biological tissues. ${ }^{20}$ FT-IR analysis of bacteria grown at experimental concentrations displayed significant peak differences in spectra compared with the 0 $\mathrm{mg} / \mathrm{L}$ control sample (Fig. 2B-2D). We observed that amide I $\left(1655 \mathrm{~cm}^{-1}\right)$ and amide II $\left(1544 \mathrm{~cm}^{-1}\right)$ peaks greatly decreased in intensity for the $3000 \mathrm{mg} / \mathrm{L}$ sample after 3 days. A similar result was also observed for the $100 \mathrm{mg} / \mathrm{L}$ sample after 3 days, but not for day 0 and day 1 . However, for the 0 and $40 \mathrm{mg} / \mathrm{L}$ samples, there was no such peak difference among the spectra with respect to different days. While distinct peaks are expected to be observed for $\mathrm{S}-\mathrm{O}$ stretching vibrations of SDS for experimental samples in the region of 1250-1200 $\mathrm{cm}^{-1},{ }^{21}$ no such peaks were observed for those samples.

FT-IR second-derivative analysis revealed several notable peak shifts in the second-derivative spectra of day 3 samples as compared with day 0 , especially for higher concentrations of SDS (Figs. 3C 3D). Figure 4 shows a representative spectrum for curve-fitting analysis, which displays how the protein secondary-structure subgroups are divided in amide I region. Using those peaks as reference, we estimated values of percentile area under curve for each subgroup peak with respect to the total peak area. Table 1 details how the percentage areas for the defined subgroups were affected by the presence of SDS. The area-percentage values were not always consistent for different samples, especially since SDS can directly contribute to the prevalence of certain peaks, but several trends are apparent in the curve-fitting results. In particular, the $40 \mathrm{mg} / \mathrm{L}$ sample showed a slight increase for the total $\beta$-sheet area-percentage values on day 3 as compared with day 0 . For the $100 \mathrm{mg} / \mathrm{L}$ sample, in comparison with day 0 values, there was a remarkable increase for the total $\beta$-sheet and a slight decrease for the $\alpha$-helix area-percentage values on day 3. For the $3000 \mathrm{mg} / \mathrm{L}$ sample, a completely different behavior occurs where a remarkable increase for the $\alpha$-helix and a slight decrease for the total $\beta$-sheet area-percentage values was observed on day 3. Furthermore, the areapercentage values of turns were considerably increased, and the area-percentage values for aromatic ring structures were consistently and unexpectedly higher during experimental period for all SDS-containing samples.

Effects of High Concentrations of Sodium Dodecyl Sulfate (SDS) on Bacterial Cell Morphology. SDS in 3000 $\mathrm{mg} / \mathrm{L}$ concentration appears to induce stress conditions for $A$. butzleri, since the growth of bacteria was negatively affected 

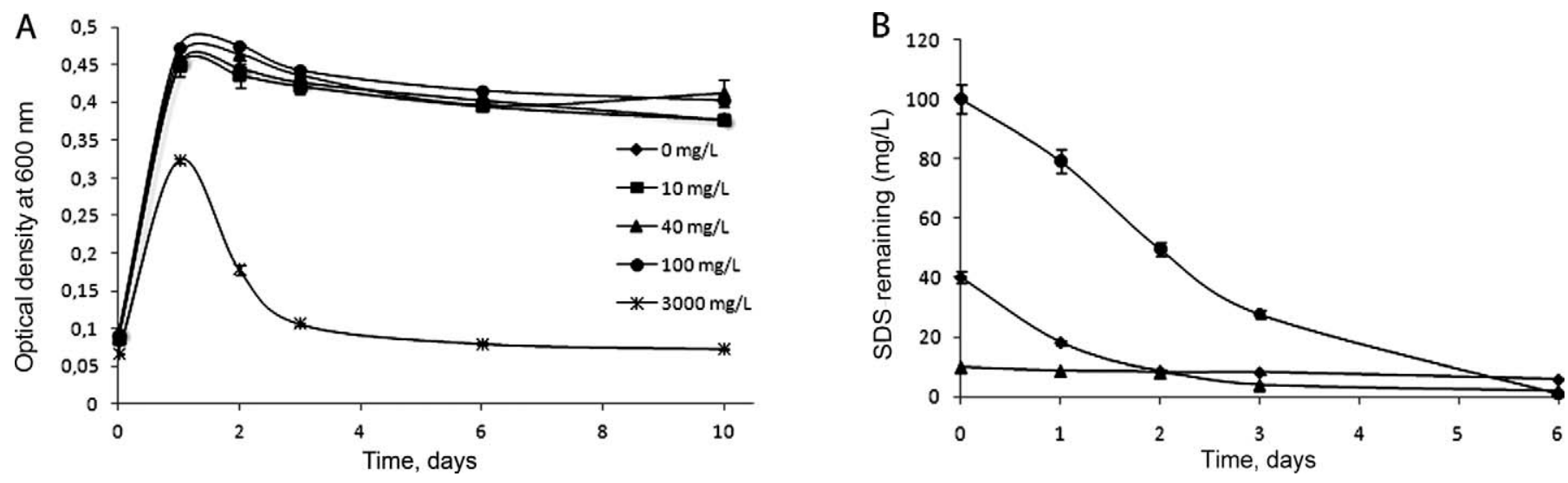

FIG. 1. Growth curve (A) and biodegradation of SDS (B) by A. butzleri in 10 and 6 days, respectively, at different concentrations of SDS (10, 40 , and 100 mg/L). An error bar $=$ mean $\pm \operatorname{SEM}(n=3)$.

(Fig. 1A). This concentration was used to observe the effects of high concentrations of SDS on bacterial cell morphology. SEM images of the $3000 \mathrm{mg} / \mathrm{L}$ sample revealed that, in contrast to the smoother cell walls of unstressed control samples, small burrs were present on bacterial cell walls after $48 \mathrm{~h}$ of exposure (Figs. 5A and 5B).

\section{DISCUSSION}

Biological Removal of Sodium Dodecyl Sulfate (SDS). In a previous study, Shukor and colleagues report that a novel Klebsiella oxytoca isolate successfully degraded up to 2000 $\mathrm{mg} / \mathrm{L}$ SDS in 10 days, under optimized conditions. ${ }^{22}$ In our
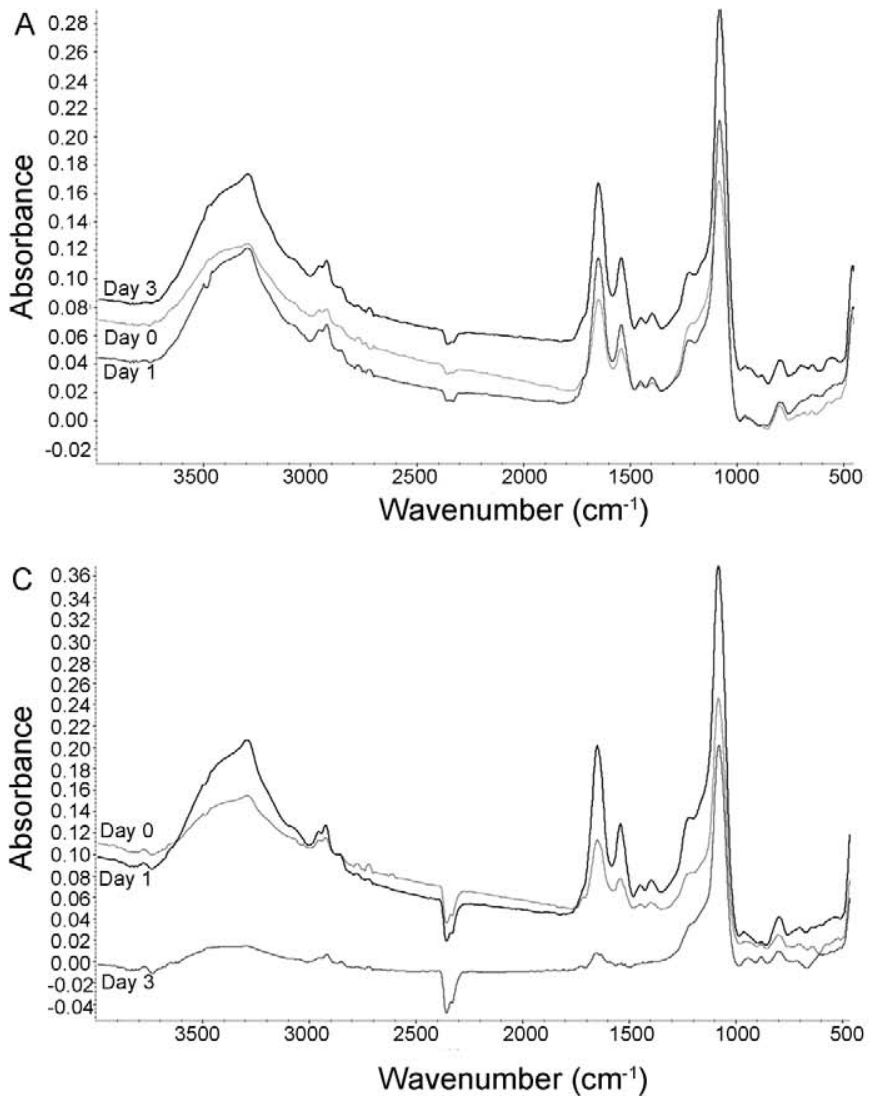

study, while a concentration range of 10-3000 mg/L SDS (10, $40,100,1000,2000$, and 3000) was initially tested, it was found that the $A$. butzleri isolate could not effectively degrade SDS concentrations above $100 \mathrm{mg} / \mathrm{L}$ under experimental conditions. Moreover, it was observed that this isolate could not survive at extremely high concentrations of SDS, with nearly complete inhibition of growth at $3000 \mathrm{mg} / \mathrm{L}$ SDS. However, the isolate displayed efficient SDS biodegradation at concentrations up to $100 \mathrm{mg} / \mathrm{L}$ within 6 days (Fig. 1B). Since the legal limit for anionic surfactants in wastewater is much lower than our experimental conditions $(\leq 5 \mathrm{mg} / \mathrm{L}$ for anionic surfactants), ${ }^{7}$ and surfactant contamination levels are below
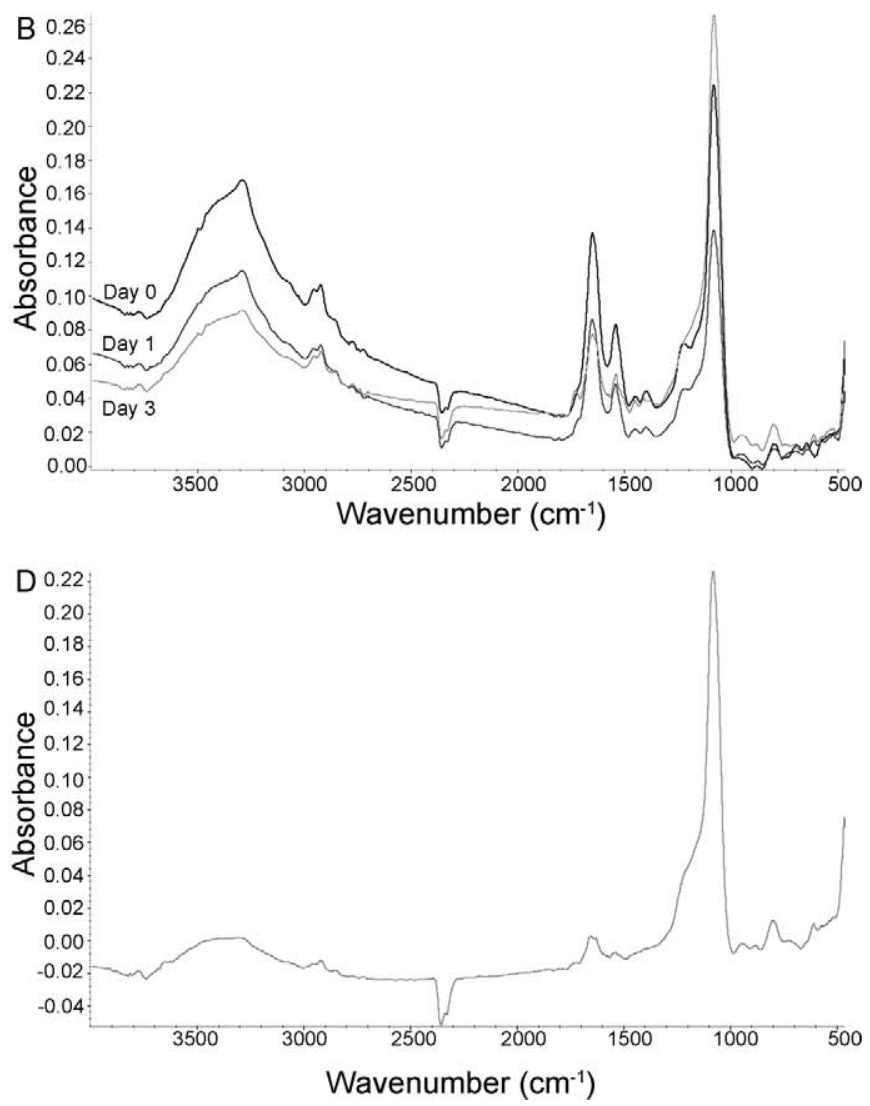

FIG. 2. FT-IR spectra of A. butzleri grown at $0(\mathbf{A}), 40(\mathbf{B})$, and 100 (C) on days 0,1 , and 3, and $3000 \mathrm{mg} / \mathrm{L}$ SDS (D) on day 3. 

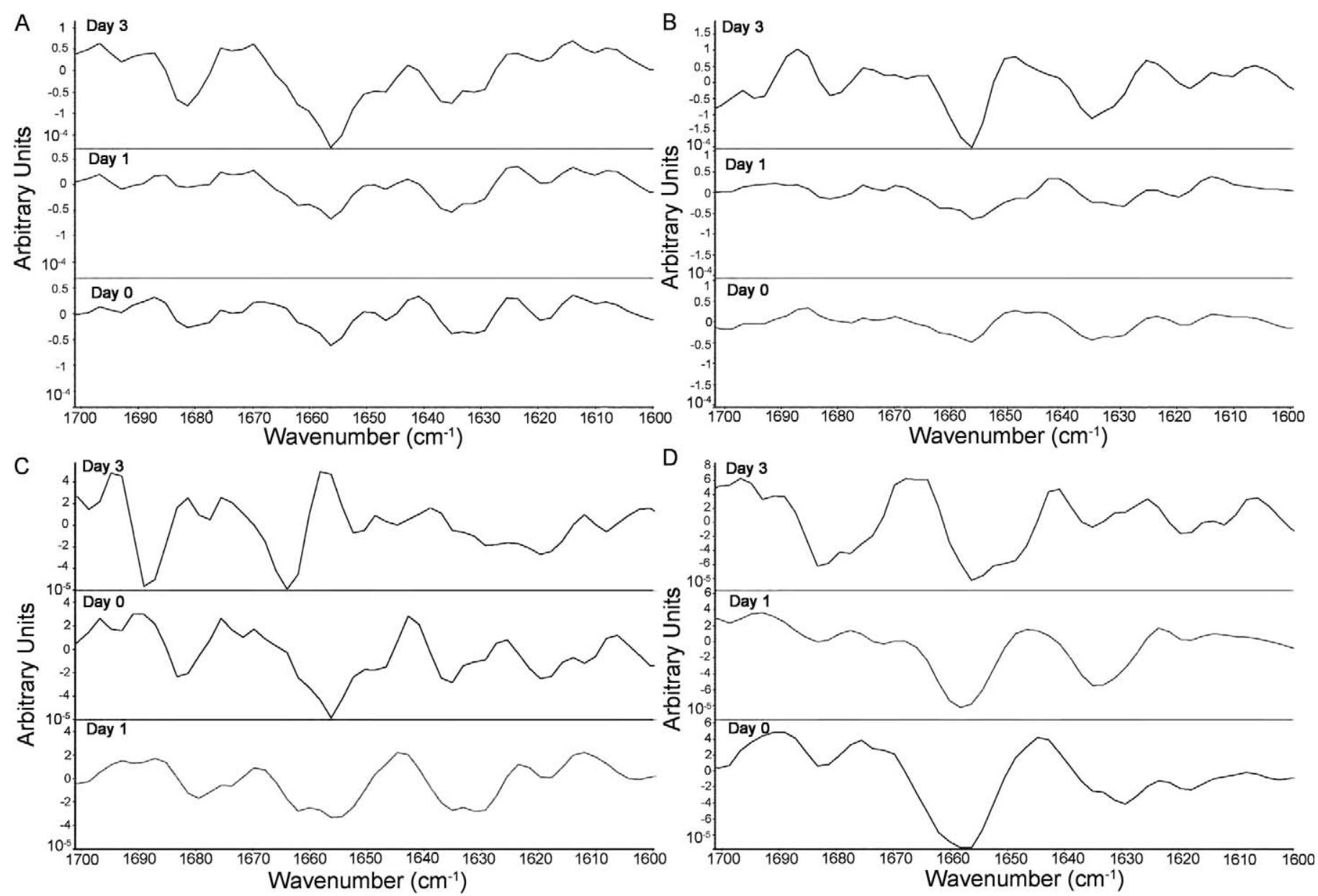

FIG. 3. FT-IR second-derivative spectra of the amide I region of $A$. butzleri grown at 0 (A), 40 (B), 100 (C), and $3000 \mathrm{mg} / \mathrm{L}$ SDS (D) on days 0 , 1 , and 3 .

$100 \mathrm{mg} / \mathrm{L}$ in many cases, the A. butzleri isolate has the potential for use in biological treatment of wastewater systems. It is particularly notable that bacteria grown in LB medium containing $100 \mathrm{mg} / \mathrm{L}$ SDS degraded this surfactant more efficiently ( $99 \%$ in 6 days) compared with samples subjected to lower initial SDS concentrations $(80 \%$ removal for $10 \mathrm{mg} / \mathrm{L}$ and $85 \%$ removal for $40 \mathrm{mg} / \mathrm{L}$ samples). This result indicates

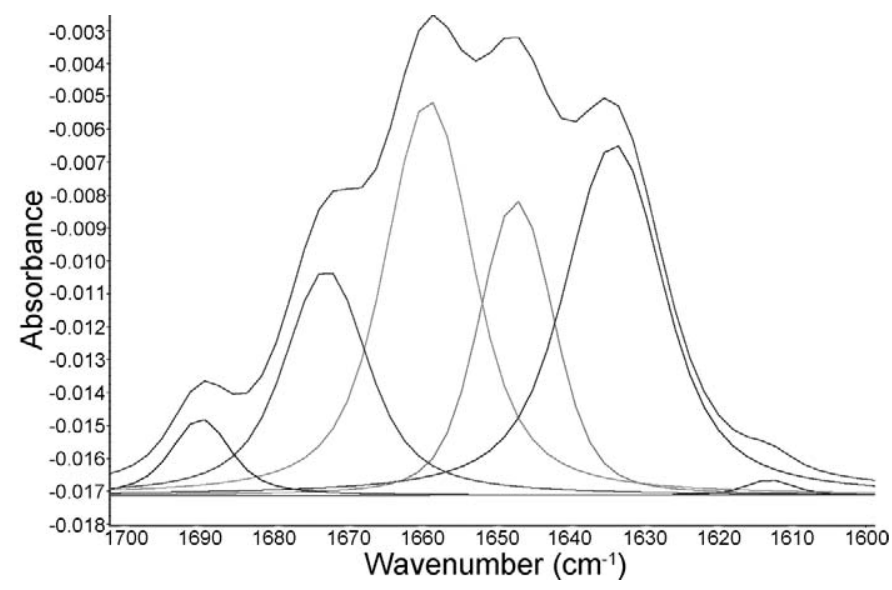

FIG. 4. Representative spectrum of the amide I region as a result of curvefitting analysis of the $0 \mathrm{mg} / \mathrm{L}$ sample on day 1 , showing the distribution of protein secondary structures that are analyzed in this study. that at certain concentration ranges, SDS does not reduce the biodegradation capacity; on the contrary, it seems to support this process by enhancing metabolic activity. The growth curves of bacteria for each experimental concentration are very similar, which suggests the presence of SDS in the growth medium at concentrations between 10 and $100 \mathrm{mg} / \mathrm{L}$ does not have a significant effect on bacterial growth, and the increase in degradation rate could be caused by changes in the expression of detergent-metabolizing genes instead.

Biochemical Alterations in Bacteria During Sodium Dodecyl Sulfate (SDS) Biodegradation. FT-IR was utilized to screen the effects of SDS biodegradation on bacteria, as a novel approach. Photometric tests such as the MBAS assay or chromatographic analyses such as HPLC can be performed for screening surfactant biodegradation; however, to screen biochemical interactions and alterations that occur as a result of those interactions, spectroscopic studies such as circular dichroism, Raman, and FT-IR methods are more suitable options. Since FT-IR is simple to perform and allows rapid analysis of chemical interactions that take place in bacterial cells, this technique was chosen for further analysis. Our aim was to observe differences in specific chemical bonds and groups as a result of biodegradation process by applying FT-IR, especially at higher concentrations of SDS. FT-IR was also utilized to screen specific peaks for the metabolites of SDS (e.g., dodecanol and lauryl acid) and the effects of them together with SDS itself on the biochemistry of the SDS-metabolizing bacterial isolate. 

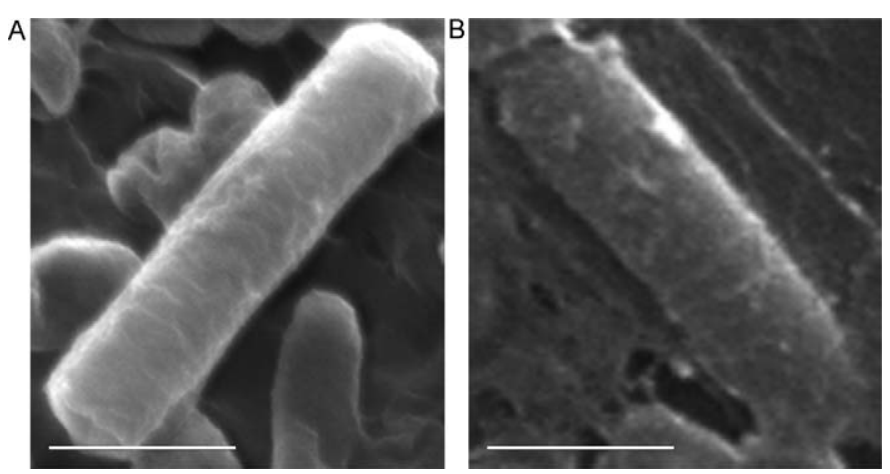

FIG. 5. SEM images of single A. butzleri cells: (A) corresponds to nonstressed bacterium, and (B) corresponds to SDS stressed bacterium that was grown in $3000 \mathrm{mg} / \mathrm{L}$ SDS-containing medium. One bar $=1 \mu \mathrm{m}$.

Although we could not observe specific peaks for neither SDS nor its metabolites due to peak overlapping, we observed several significant peak differences in protein structure-related spectra of the experimental samples, indicating that protein synthesis is altered in the presence of SDS. For instance, at higher SDS concentrations (100 and $3000 \mathrm{mg} / \mathrm{L}$ ), amide I and amide II peaks, which correspond to the protein content of the bacterial cell, are greatly reduced in intensity (Figs. 2C and 2D). This change in the amide regions can be explained by protein denaturation - in other words, alterations in the secondary structures of proteins. ${ }^{23}$ The anionic head group of SDS and positively charged proteins interact electrostatically. Moreover, the tails of SDS and proteins both have hydrophobic characteristics and can participate in hydrophobic interactions. Therefore, it is likely that SDS and its metabolites interact with proteins via hydrophobic and electrostatic interactions and alter their secondary structures at sufficiently high concentrations, which could lead to the observed changes in the amide I and amide II regions. ${ }^{24}$ In a recent study by Rocha and colleagues, a similar behavior was observed for peptide amyloid- $\beta$. When surface pressure in the environment decreased to a certain level due to the presence of surfactants, amide I and amide II peaks of amyloid- $\beta$ disappear, according to IR reflection absorption spectroscopy. ${ }^{25}$ Finally, the expected peaks of SDS in the region of $1250-1200 \mathrm{~cm}^{-1}$ (S-O stretching vibrations) were not seen in the experimental samples. This is probably due to peak overlapping, such that $\mathrm{CH}_{2}$ stretching of the bacterial carbohydrates leads to a spectral overlap and makes it impossible to detect $\mathrm{S}-\mathrm{O}$ stretching vibrations, which are specific to SDS. ${ }^{19,20}$

For protein secondary-structure analysis, we emphasize the shifts in peak locations and changes in the area-percentage values for 100 and $3000 \mathrm{mg} / \mathrm{L}$ samples, since only those two samples showed a sharp decrease in intensity at amide I and amide II regions. In addition, there is a significant peak shift at the amide I region for 100 and $3000 \mathrm{mg} / \mathrm{L}$ samples in comparison with the control sample (Figs. 3C and 3D). Table I shows the influence of SDS concentrations on protein secondary structures. It is notable that the percentages of aromatic rings were higher during the initial days, especially for samples with higher SDS concentrations, which is possibly due to the presence of SDS. Protein secondary structures were altered in different ways for higher SDS concentrations (100 and $3000 \mathrm{mg} / \mathrm{L}$ samples). It is also particularly notable that the $40 \mathrm{mg} / \mathrm{L}$ sample generally displayed a tendency similar to the $100 \mathrm{mg} / \mathrm{L}$ sample. For the $100 \mathrm{mg} / \mathrm{L}$ sample, the ratio of total $\beta$-sheet structures considerably increases while a slight 
decrease in $\alpha$-helix structure was observed. On the contrary, for $3000 \mathrm{mg} / \mathrm{L}$ sample, the ratio of $\alpha$-helix structures considerably increased, while a slight decrease in total $\beta$-sheet structure was present. Therefore, as expected from the general spectra of those two samples, protein secondary structures were highly altered on day 3 in comparison with the initial day. In addition, it was observed that SDS can either be responsible for a drift toward $\beta$-sheet or $\alpha$-helix formation on a concentrationdependent manner. This is likely because while lower concentrations of SDS can be tolerated by the isolate and as such, trigger expression of proteins related to surfactant biodegradation, higher levels of SDS are toxic and likely result in upregulation of stress tolerance genes, as well as denaturation of cellular proteins. The gradual and considerable increase in the area-percentage values of turns (Table I) in a surfactant concentration-dependent manner supports the idea that SDS is responsible for denaturation of proteins in bacteria. ${ }^{26}$ In particular, the comparative increase in turns for the 100 and especially the $3000 \mathrm{mg} / \mathrm{L}$ samples on day 3 is attributable to denatured proteins. Therefore, differential protein expression and denaturation could have contributed to the marked differences observed between protein secondary structures of 100 and $3000 \mathrm{mg} / \mathrm{L}$ samples on day 3 .

Effects of High Concentrations of Sodium Dodecyl Sulfate (SDS) on Bacterial Cell Morphology. SEM images of $A$. butzleri samples were taken to see the effects of high concentration of SDS on bacterial cell morphology. We observed that high concentration of SDS $(3000 \mathrm{mg} / \mathrm{L})$ caused small burrs on bacterial cell walls. While the general morphologies of control and SDS-stressed bacteria were very similar, the amount of grown bacteria in the medium was significantly lower for the latter sample, and the cell wall was not as smooth as the control sample for stressed bacteria. It is likely that the presence of high concentration of SDS in the medium is the reason for this difference, either by directly acting on the cell membrane or by causing alterations in the expression of various genes as a defense mechanism on part of the isolate.

The Potential Use of the $A$. butzleri Isolate for Bioremoval of Anionic Surfactants. Arcobacter is widely found in aquatic environments such as river waters, drinkingwater reservoirs, and canal waters, ${ }^{27}$ and can thrive in sewage and wastewater treatment plants where other living organisms are either absent or found in very low numbers. Therefore, we conclude that the A. butzleri isolate described in this paper can be utilized for bioremediation of anionic surfactants, either by itself or in a bacterial consortium similar to the one presented by Abboud and colleagues. ${ }^{28}$

\section{ACKNOWLEDGMENTS}

We thank Turgay Cakmak and Yavuz S. Dagdas for technical assistance. This work is supported by grants from the State Planning Organization of Turkey (DPT) and Şişecam Group.

1. R.A. Goodnow, A.P. Harrison, Jr. "Bacterial Degradation of Detergent Compounds". Appl. Microbiol. 1972. 24(4): 555-60.

2. EPA. "Fate and Transport of Nonionic Surfactants". 1999-2001. http:// cfpub.epa.gov/ncer_abstracts/index.cfm/fuseaction/display.abstractDetail/ abstrac t/5703 [accessed: March 2011].

3. M.J. Scott, M.N. Jones. "The Biodegradation of Surfactants in the Environment". Biochim. Biophys. Acta. 2000. 1508(1-2): 235-251.

4. N.O. Mwebi. Fenton and Fenton-like reactions: the nature of oxidizing intermediates involved. [Ph.D. Thesis]. College Park, Maryland: University of Maryland, 2005.

5. Bionewsonline. "What is Bioremediation?. 2005. http://www. bionewsonline.com/w/ what_is_bioremediation.htm [accessed: December 2012].

6. Y. Azov, G. Shelef, N. Narkis. "Effect of Hard Detergents on Algae in a High-Rate-Oxidation Pond". Appl. Environ. Microbiol. 1982. 43(2): 491492.

7. A. Dhouib, N. Hamad, I. Hassairi, S. Sayadi. "Degradation of Anionic Surfactants by Citrobacter braakii". Process Biochem. 2003. 38(8): 12451250.

8. P. Vandamme, M. Vancanneyt, B. Pot, L. Mels, B. Hoste, D. Dewettinck, L. Vlaes, C. van den Borre, R. Higgins, J. Hommez, K. Kersters, J.P. Butzler, H. Goossens. "Polyphasic Taxonomic Study of the Emended Genus Arcobacter with Arcobacter butzleri comb. nov. and Arcobacter skirrowii sp. nov., an Aerotolerant Bacterium Isolated from Veterinary Specimens". Int. J. Syst. Bacteriol. 1992. 42(3): 344-356.

9. N.K. Kosaric. "Biosurfactants and Their Application for Soil Bioremediation". Food Tech. Biotech. 2001. 39(4): 295-30.

10. L. Otth, G. Solis, M. Wilson, H. Fernandez. "Susceptibility of Arcobacter butzleri to Heavy Metals". Braz. J. Microbiol. 2005. 36(3): 286-288.

11. O. Abbas, C. Rebufa, N. Dupuy, J. Kister. "FTIR-Multivariate Curve Resolution Monitoring of Photo-Fenton Degradation of Phenolic Aqueous Solutions Comparison with HPLC as a Reference Method". Talanta. 2008. 77(1): 200-209.

12. T.S. Bhalerao, P.R. Puranik. "Microbial Degradation of Monocrotophos by Aspergillus oryzae". Int. Biodetr. Biodegr. 2009. 63(4): 503-508.

13. B. Harrass, S. Schwarz, S. Wenzel. "Identification and Characterization of Arcobacter Isolates from Broilers by Biochemical Tests, Antimicrobial Resistance Patterns, and Plasmid Analysis". J. Vet. Med. B Infect. Dis. Vet. Public Health. 1998. 45(2): 87-94.

14. J. Sambrook, E.F. Fritsch, T. Maniatisi. Molecular Cloning-a Laboratory Manual. New York: Cold Spring Harbor Laboratory Press, 1989. 2nd Edition.

15. A.R. Poteete, H.R. Wang, P.L. Foster. "Phage $\lambda$ Red-Mediated Adaptive Mutation". J. Bacteriol. 2002. 184(13): 3753-3755.

16. H.I. Atabay, A. Unver, M. Sahin, S. Otlu, M. Elmali, H. Yaman. "Isolation of Various Arcobacter Species from Domestic Geese (Anser anser)". Vet. Microbiol. 2002. 128(3-4): 400-405.

17. K. Hayashi. "A Rapid Determination of Sodium Dodecyl Sulfate with Methylene Blue". Anal. Biochem. 1975. 67(2): 503-506.

18. C. Chadefaux, A.S.L. Hô, L.B. Gurlet, I. Reiche. "Curve Fitting MicroATR-FTIR Studies of the Amide I and Amide II Bands of Type I Collagen in Archeological Bone Materials". e-PreservationScience.org. 2009. 6: 129137.

19. D. Greif, D. Wesner, J. Regtmeier, D. Anselmetti. "High-Resolution Imaging of Surface Patterns of Single Bacterial Cells". Ultramicroscopy. 2010. 110(10): 1290-1296.

20. Z. Movasaghi, S. Rehman, I.U. Rehman. "Raman Spectroscopy of Biological Tissues". Appl. Spectrosc. Rev. 2007. 42(5): 493-541.

21. D.R. Scheuing, J.G. Weers. "A Fourier Transform Infrared Spectroscopic Study of Dodecyltrimethylammonium Chloride/Sodium Dodecyl Sulfate Surfactant Mixtures". Langmuir. 1990. 6(3): 665-671.

22. M.Y. Shukor, W.S.W. Husin, M.F.A. Rahman, N.A. Shamaan, M.A. Syed. "Isolation and Characterization of an SDS-Degrading Klebsiella oxytoca". J. Environ. Biol. 30(1): 129-134.

23. J. Kong, Y.U. Shaoning. "Fourier Transform Infrared Spectroscopic Analysis of Protein Secondary Structure". Acta Biochim. Biophys. Sin. 2007. 39(8): 549-559.

24. L. Hugonin, A. Barth, A. Graslund, A. Peralvarez-Marin. "Secondary Structure Transitions and Aggregation Induced in Dynorphin Neuropeptides by the Detergent Sodium Dodecyl Sulfate". Biochim. Biophys. Acta. 2008. 1778(11): 2580-2587.

25. S. Rocha, J.A. Loureiro, G. Brezesinski, M. do Carmo Pereira. "PeptideSurfactant Interactions: Consequences for the Amyloid- $\beta$ Structure". Biochem. Biophys. Res. Commun. 2012. 420(1): 136-140.

26. B. Elibol-Can, E. Jakubowska-Dogru, M. Severcan, F. Severcan. "The Effects of Short-Term Chronic Ethanol Intoxication and Ethanol Withdrawal on the Molecular Composition of the Rat Hippocampus by FT-IR Spectroscopy”. Aclcohol Clin. Exp. Res. 2011. 35(11): 2050-2062.

27. M.T. Fera, T.L. Maugeri, M. Giannone, C. Gugliandolo, E. La Camera, G. Blandino, M. Carbone. "In Vitro Susceptibility of Arcobacter butzleri and Arcobacter cryaerophilus to Different Antimicrobial Agents". Int. J. Antimicrob. Agents. 2003. 21(5): 488-491.

28. M.M. Abboud, K.M. Khleifat, M. Batarseh, K.A. Tarawneh, A. AlMustafa, M. Al-Madadhah. "Different Optimization Conditions Required for Enhancing the Biodegradation of Linear Alkylbenzosulfonate and Sodium Dodecyl Sulfate Surfactants by Novel Consortium of Acinetobacter calcoaceticus and Pantoea agglomerans". Enzyme Microb. Technol. 2007. 41(4): 432-439. 